\title{
Exercise-Induced Bronchoconstriction in Children
}

\author{
Angela Klain*, Cristiana Indolfi, Giulio Dinardo, Marcella Contieri, Fabio Decimo and \\ Michele Miraglia Del Giudice
}

Department of Woman, Child and General and Specialized Surgery, University of Campania "Luigi Vanvitelli", Naples, Italy

Exercise-induced bronchoconstriction (EIB) is a transient airflow obstruction, typically 5-15 min after physical activity. The pathophysiology of EIB is related to the thermal and osmotic changes of the bronchial mucosa, which cause the release of mediators and the development of bronchoconstriction in the airways. EIB in children often causes an important limitation to physical activities and sports. However, by taking appropriate precautions and through adequate pharmacological control of the condition, routine exercise is extremely safe in children. This review aims to raise awareness of EIB by proposing an update, based on the latest studies, on pathological mechanisms, diagnosis, and therapeutic approaches in children.

Keywords: exercise-induced bronchoconstriction, exercise induced asthma, children, asthma, atopy

\section{OPEN ACCESS INTRODUCTION}

Edited by:

Sara Manti,

University of Catania, Italy

Reviewed by:

Amelia Licari,

University of Pavia, Italy

Giuliana Ferrante,

University of Verona, Italy

${ }^{*}$ Correspondence:

Angela Klain

klainangela95@gmail.com

Specialty section:

This article was submitted to

Pulmonary Medicine,

a section of the journal

Frontiers in Medicine

Received: 14 November 2021 Accepted: 09 December 2021 Published: 03 January 2022

Citation:

Klain A, Indolfi C, Dinardo G,

Contieri M, Decimo F and Miraglia Del

Giudice M (2022) Exercise-Induced Bronchoconstriction in Children.

Front. Med. 8:814976.

doi: 10.3389/fmed.2021.814976
EIB is a condition of bronchoconstriction of the airways following intense physical activity, that may occur in people with or without bronchial asthma. EIB has been for years defined also with the acronym EIA (exercise-induced asthma). The two terms, however, indicate two different clinical conditions: EIA is a real pathology, characterized by bronchial hyperactivity and chronic inflammation, while the EIB represents the transitory airway narrowing, that may also occur in non-asthmatic patients. The two conditions also differ therapeutically: EIA benefits from corticosteroid treatment to manage the underlying chronic inflammation, while EIB, in most cases, is managed with a short-acting b2-agonist before exercise. Therefore, although the two terms have long been interchangeable, currently, it is preferred to talk about EIB, as most asthmatic people have EIB, but not all patients with EIB have asthma (1).

Symptoms of EIB are not characteristic and include dyspnea, cough, shortness of breath, wheezing, and chest pain. Some clinical conditions such as exercise-induced laryngeal obstruction (EILO), respiratory model disorders, chest wall restrictions, and cardiovascular pathologies, may mimic EIB symptoms. EILO often occurs in young female adolescents with dyspnea with or without stridor during exercise and is detected by laryngoscopy during treadmill test (continuous laryngoscopy exercise) (2). Breathing pattern disorders (the most frequent is the hyperventilation syndrome) are characterized by dyspnea on exertion or at rest, associated or not with organic diseases; the diagnosis requires multidisciplinary evaluation, including a psychophysiological approach (3). Chest wall restrictions are congenital or acquired conditions that limit the expansion of the rib cage, causing a sense of 'air hunger at rest or after physical exertion (4). Cardiovascular pathologies such as supraventricular tachycardia, cardiomyopathy, cyanotic and acyanotic structural congenital heart diseases can cause dyspnea and chest pain $(5,6)$. Cardiopulmonary exercise test, which measures ventilation, oxygen consumption (VO2), carbon dioxide production (VCO2), pulse oximetry, and flowvolume loops during and after exertion, is essential for identifying forms of dyspnea related 
to alterations of cardiovascular, pulmonary, and musculoskeletal systems (7).

EIB is observed in $40-90 \%$ of asthmatic children, especially in those with severe asthma not pharmacologically controlled (8-11).

Furthermore, EIB is prevalent in athletes who play endurance sports (12), reaching a prevalence of $55 \%$ in winter sports athletes (13).

Atopy is the main risk factor, as demonstrated by epidemiological data showing that among children with EIB, up to $40 \%$ of them have allergic rhinitis and $30 \%$ can develop asthma in the adult, following the march atopic (14).

There is some evidence that supports that eosinophilic airway inflammation is associated with EIB in asthmatic children and FeNO (Fractional Exhaled Nitric Oxide) levels correlate to EIB severity (15). According to some authors, FeNO values could be used as a predictor of EIB in asthmatic children (16), in particular, low eNO may be used as a negative predictor for EIB (17). According to Buchvald et al. EIB could be excluded with a probability of $90 \%$ for FeNO50 levels $<20$ p.p.b., in subjects not currently using inhaled corticosteroids, and $<12$ p.p.b. in those currently using inhaled corticosteroids (18).

In the pediatric age, atopic dermatitis (11), sensitization to indoor allergens (19), elevated levels of both seasonal and perennial IgE (20) appear to be associated with an increased risk of developing EIB.

Environmental factors such as exposure to cold air, high atmospheric pressures, humidity, and pollutants are related to an increased risk of developing EIB (21-23).

\section{PATHOPHYSIOLOGY AND MECHANISMS UNDERLYING EIB}

When triggering factors are present, such as cold and dry air, pollutants, allergens, exercise causes increased ventilation causing dehydration of the airways mucosa, resulting in increased osmolarity, contraction of bronchial smooth muscle, and an influx of eosinophils and mast cells that release inflammatory mediators (leukotrienes, histamine, IL-8, tryptase, and prostaglandins) (24). These signaling molecules increase airway smooth muscle contraction, mucus production, microvascular permeability, and sensory nerve activation, representing the primary stimulus for bronchoconstriction and airway edema $(25,26)$.

Neurological factors are also implicated in the pathophysiology of EIB. The sensory nerves are activated directly by osmotic stimuli; in addition, prostaglandins can also directly activate or alter the activation threshold of sensory nerves. In the UK, Maher et al. have shown that PGD2, which is predominantly produced by mast cells, initiates the activation of sensory nerves via the DP1 receptor, regulating the tone of the airways (27). Furthermore, there is evidence that neurokinin A and CysLT levels in the airways are correlated with the degree of bronchoconstriction after exercise and with the release of mucins, particularly MUC5AC which is more expressed in the sputum of patients with bronchoconstriction after exercise (28) (Figure 1).

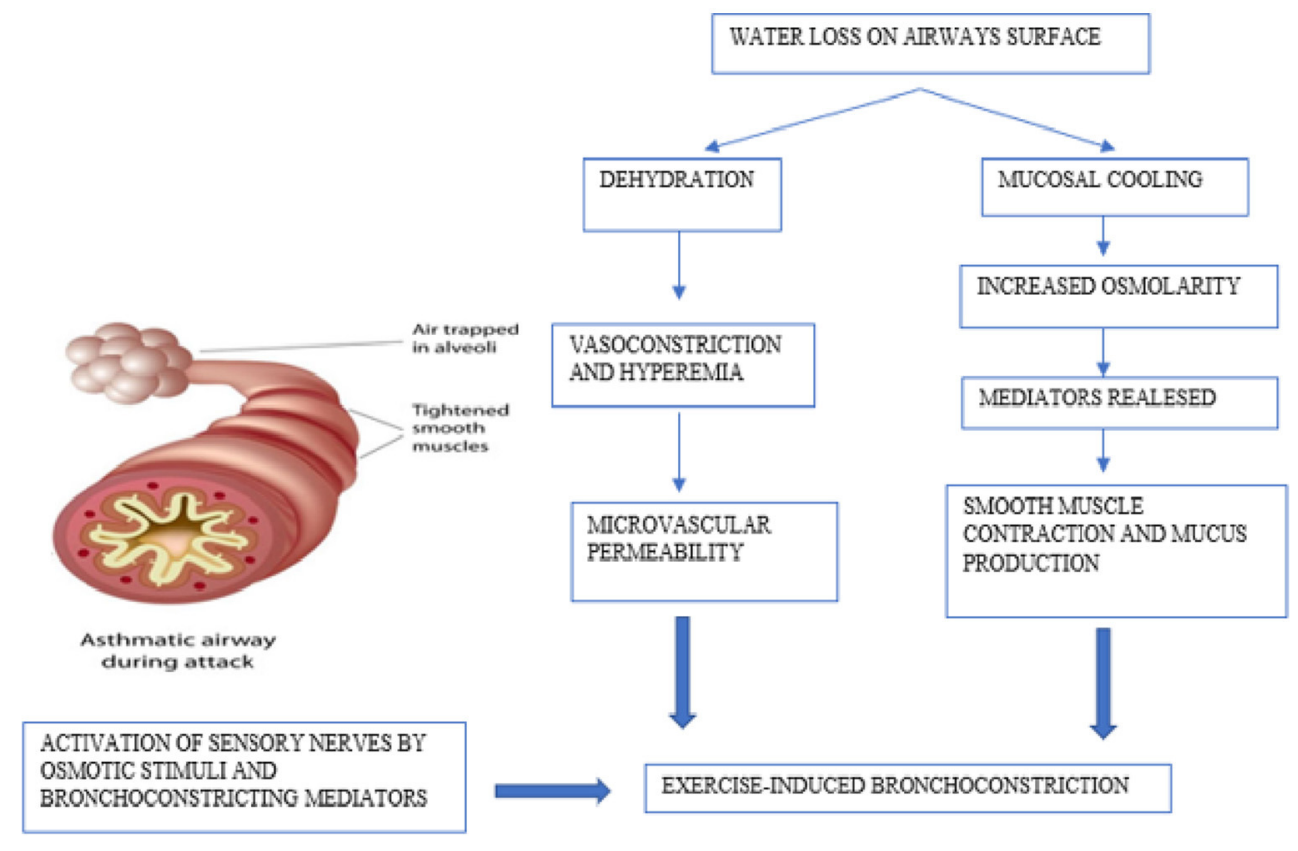

FIGURE 1 | Pathophysiology and mechanisms underlying exercise-induced bronchoconstriction. 


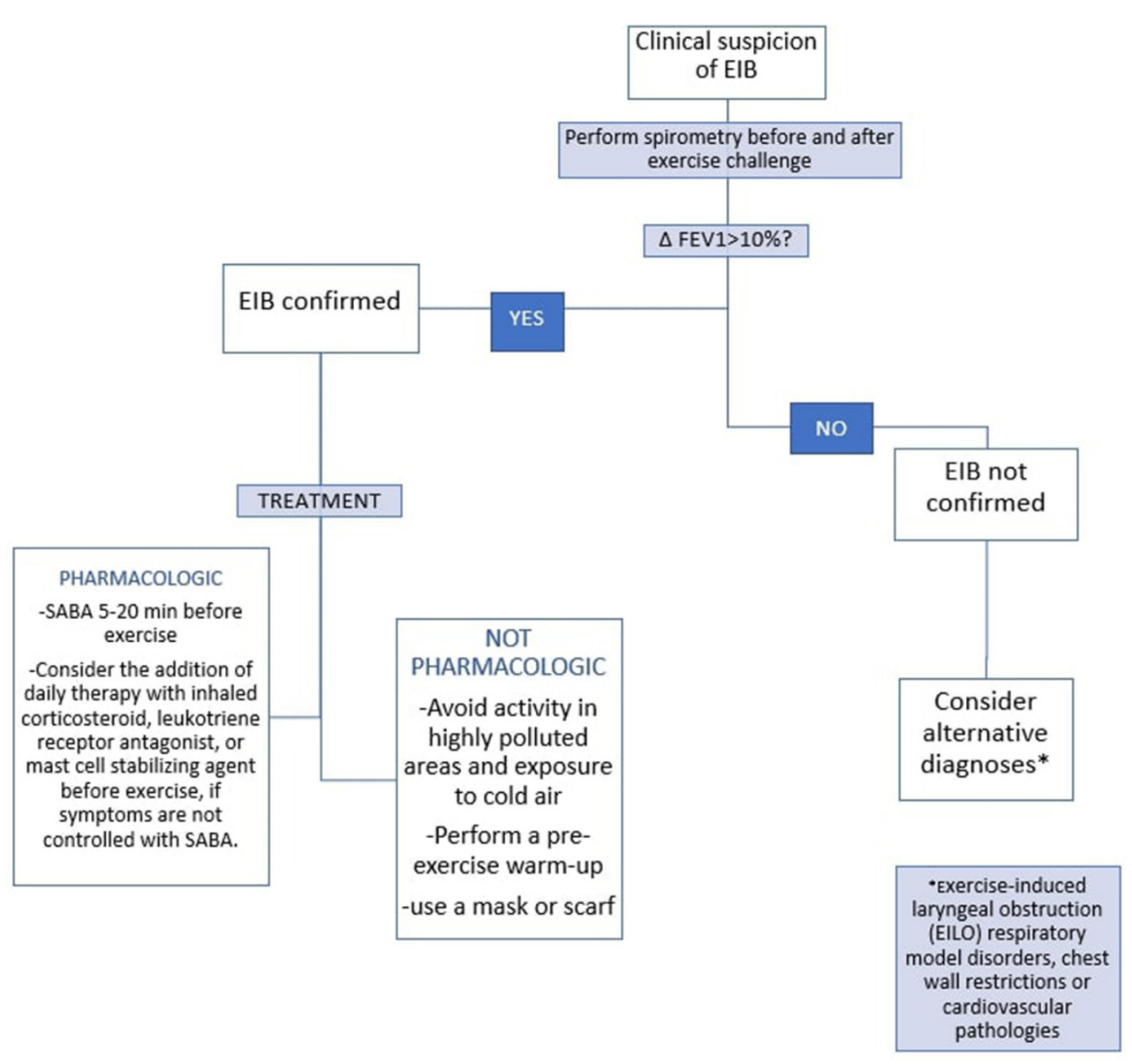

FIGURE 2 | EIB flow chart in children, according to ATS.

\section{DIAGNOSIS}

In 2019 Lammers et al. conducted a study about the ability of pediatricians to assess EIB from anamnesis and physical examination: the sensitivity of a pediatrician's predicted diagnosis of BEI was $84 \%$, compared with a specificity of $24 \%$; EIB severity prediction was poor, with many serious cases underestimated (29). In 2020 the same authors have studied the ability of pediatricians to assess EIB from post-exercise videos, comparing it to EIB severity assessed by the exercise challenge test (ECT) (30). The study found a positive predictive value for pediatricians' diagnosis of BEI of $61 \%$ and a negative predictive value was $60 \%$. These studies show that pediatricians have at best a fair ability to assess EIB severity from symptoms and post-exercise videos, implicating that standardized ECT is still fundamental in the diagnosis of EIB.

Spirometry after exercise challenge test is considered the gold standard for the diagnosis of EIB. According to ATS (American Thoracic Society)/European Respiratory Society guidelines, at least two FEV1 (forced expiratory volume in the 1st s) maneuvers must be measured pre and after exercise challenge (e.g., treadmill). FEV1 is usually measured at 5, 10, 15, and $30 \mathrm{~min}$ after exercise. A difference between the pre-exercise FEV1 value and the lowest FEV1 value recorded within 30 min after exercise $>10 \%$ is diagnostic of $\operatorname{EIB}(24,31,32)$.

There are alternative tests to ECT to be used in situations where, for example, the patient cannot perform exercise tests: methacholine challenge, eucapnic voluntary hyperventilation, mannitol challenge, hypertonic saline challenge, histamine challenge (33). Nowadays, the role of these tests is still debated.

Recently, a Dutch study investigated the role of surface electromyography (EMG) to study the electrical activity of the diaphragm, as an alternative EIB diagnostic tool: EMG peak amplitudes measured at the diaphragm increased significantly more in children with EIB compared to children without EIB, suggesting a role for EMG as a non-invasive and stressindependent test to be practiced in cases where ECT is not feasible (34).

At present, there is no sufficient evidence to support the widespread adoption of any existing EIB screening tools (35).

\section{TREATMENT}

In patients with EIB, ATS recommends the use of a short-acting b2-agonist (SABA) 5-20 min before exercise. For patients who 
continue to have symptoms of EIB despite the administration of SABA before exercise, daily inhaled corticosteroid, daily leukotriene receptor antagonist, or mast cell stabilizing agent before exercise should be used. In allergic patients with BEI, ATS recommends the use of antihistamines in addition to therapy with SABA (24).

EIB in asthmatic children often causes an important limitation to physical activities and sports. However, by taking appropriate precautions (avoiding or reducing activity in highly polluted areas, exposure to cold air, performing a preexercise warm-up and regular physical activity, and through adequate pharmacological control of asthma), exercise routinely is extremely safe in children (36). Some studies have shown that regular continuous aerobic exercise benefits asthmatic patients on FEV1, PEF, FVC, FEF $25-75 \%$ and, in general, improves patients' symptoms and quality of life (37). In childhood, EIA causes QoL (quality of life) impairment (38). A Swedish study of adolescents with or without asthma demonstrated a significant association between spirometry-defined EIB and reduced QoL (39). Routine physical exercise improves childhood EIB (including QoL) and, therefore, should be recommended as a supplementary therapy to drugs (36).

\section{REFERENCES}

1. ACAAI Public Website. Exercise-Induced Bronchoconstriction (EIB). (2021). Available online at: https://acaai.org/asthma/types-of-asthma/exerciseinduced-bronchoconstriction-eib/. (accessed November 29, 2021).

2. Nordang L, Norlander K, Walsted ES. Exercise-induced laryngeal obstruction-an overview. Immunol Allergy Clin North Am. (2018) 38:271-80. doi: 10.1016/j.iac.2018.01.001

3. Vidotto LS, Carvalho CRF, Harvey A, Jones M. Dysfunctional breathing: what do we know? J Bras Pneumol. (2019) 45:e20170347. doi: 10.1590/1806-3713/e20170347

4. Donath J, Miller A. Restrictive chest wall disorders. Semin Respir Crit Care Med. (2009) 30:275-92. doi: 10.1055/s-0029-1222441

5. Bhatia R, Abu-Hasan M, Weinberger M. Exercise-Induced dyspnea in children and adolescents: differential diagnosis. Pediatr Ann. (2019) 48:e1217. doi: 10.3928/19382359-20190219-02

6. Lands LC. Dyspnea in children: what is driving it and how to approach it. Paediatr Respir Rev. (2017) 24:29-31. doi: 10.1016/j.prrv.2017.03.013

7. Herdy AH, Ritt LE, Stein R, Araújo CG, Milani M, Meneghelo RS, et al. Cardiopulmonary exercise test: background, applicability and interpretation. Arq Bras Cardiol. (2016) 107:467-81. doi: 10.5935/abc.20160171

8. Weiler JM, Bonini S, Coifman R, Craig T, Delgado L, Capão-Filipe MP, et al. Ad Hoc committee of sports medicine committee of american academy of allergy, asthma \& immunology. American Academy of Allergy, Asthma \& Immunology Work Group report: exercise-induced asthma. J Allergy Clin Immunol. (2007) 119:1349-58. doi: 10.1016/j.jaci.2007.02.041

9. Weiler JM, Anderson SD, Randolph C, Bonini S, Craig TJ, Pearlman DS, et al. Pathogenesis, prevalence, diagnosis, and management of exercise-induced bronchoconstriction: a practice parameter. Ann Allergy Asthma Immunol. (2010). 105(Suppl. 6):S1-47. doi: 10.1016/j.anai.2010.09.021

10. McFadden ER, Jr., Gilbert IA. Exercise-induced asthma. N Engl J Med. (1994) 330:1362e7. doi: 10.1056/NEJM199405123301907

11. Lin LL, Huang SJ, Ou LS, Yao TC, Tsao KC, Yeh KW, et al. Exercise-induced bronchoconstriction in children with asthma: an observational cohort study. J Microbiol Immunol Infect. (2019) 52:471-9. doi: 10.1016/j.jmii.2017.08.013

12. Parsons JP, Kaeding C, Phillips G, Jarjoura D, Wadley G, Mastronarde JG. Prevalence of exercise-induced bronchospasm in
In Figure 2 the diagnostic and therapeutic pathway of EIB in children is summarized according to the recommendations of the ATS (Figure 2).

\section{CONCLUSION}

EIB is a very common condition in children and is related to the main atopic risk factors. In most cases, the symptoms are mild and are controlled through SABA therapy before exercise and regular physical activity. It is important to remember that untreated or mistreated EIB can have an impact on physical and psychological child growth and, therefore, requires pediatricians well-acquainted with an early recognition and therapy education of children and their families.

\section{AUTHOR CONTRIBUTIONS}

AK, CI, GD, MC, FD, and MM participated equally in the drafting of the manuscript. All authors contributed to the article and approved the submitted version.

a cohort of varsity college athletes. Med Sci Sports Exerc. (2007) 39:1487-92. doi: 10.1249/mss.0b013e3180986e45

13. Larsson K, Ohlsén P, Larsson L, Malmberg P, Rydström PO, Ulriksen H. High prevalence of asthma in cross country skiers. BMJ. (1993) 307:13269. doi: $10.1136 /$ bmj.307.6915.1326

14. Caggiano S, Cutrera R, Di Marco A, Turchetta A. Exerciseinduced bronchospasm and allergy. Front Pediatr. (2017) 5:131. doi: 10.3389/fped.2017.00131

15. Chinellato I, Piazza M, Peroni D, Sandri M, Chiorazzo F, Boner $\mathrm{AL}$, et al. Bronchial and alveolar nitric oxide in exercise-induced bronchoconstriction in asthmatic children. Clin Exp Allergy. (2012) 42:11906. doi: 10.1111/j.1365-2222.2012.03973.x

16. Grzelewski T, Grzelewska A, Majak P, Stelmach W, Kowalska A, Stelmach R, et al. Fractional exhaled nitric oxide (FeNO) may predict exercise-induced bronchoconstriction (EIB) in schoolchildren with atopic asthma. Nitric Oxide. (2012) 27:82. doi: 10.1016/j.niox.2012.05.002

17. Nishio K, Odajima H, Motomura C, Nakao F, Nishima S. Exhaled nitric oxide and exercise-induced bronchospasm assessed by FEV1, FEF25-75\% in childhood asthma. J Asthma. (2007) 44:475-8. doi: 10.1080/02770900701424090

18. Buchvald F, Hermansen MN, Nielsen KG, Bisgaard H. Exhaled nitric oxide predicts exercise-induced bronchoconstriction in asthmatic school children. Chest. (2005) 128:1964-7. doi: 10.1378/chest.128.4.1964

19. Martín-Muñoz MF, Pagliara L, Antelo MC, Madero Jarabo R, Barrio MI, Martinez MC, et al. Exercise-induced asthma in asthmatic children. Predisposing factors. Allergol Immunopathol (Madr). (2008) 36:123-7. doi: 10.1157/13124717

20. Brutsche M, Britschgi D, Dayer E, Tschopp JM. Exerciseinduced bronchospasm (EIB) in relation to seasonal and perennial specific IgE in young adults. Allergy. (1995) 50:905e9. doi: 10.1111/j.1398-9995.1995.tb02497.x

21. Anderson SD, Daviskas E. The mechanism of exercise-induced asthma is. $J$ Allergy Clin Immunol. (2000) 106:453e9. doi: 10.1067/mai.2000.109822

22. Stelmach I, Cichalewski L, Majak P, Smejda K, Podlecka D, Jerzynska J, et al. School environmental factors are predictive 478 for exercise-induced symptoms in children. Respir Med. (2016) 112:25e30. doi: 10.1016/j.rmed.2016.01.010 
23. Krafczyk MA, Asplund CA. Exercise-induced bronchoconstriction: diagnosis and management. Am Fam Physician. (2011) 84:427-34.

24. Parsons JP, Hallstrand TS, Mastronarde JG, Kaminsky DA, Rundell KW, Hull JH, et al. An official American Thoracic Society clinical practice guideline: exercise-induced bronchoconstriction Am J Respir Crit Care Med. (2013) 187:1016-27. doi: 10.1164/rccm.201303-0437ST

25. Weiler JM, Brannan JD, Randolph CC, Hallstrand TS, Parsons J, Silvers W, et al. Exercise-induced bronchoconstriction update-2016. J Allergy Clin Immunol. (2016) 138:1292-5.e36. doi: 10.1016/j.jaci.2016.05.029

26. Kippelen P, Anderson SD, Hallstrand TS. Mechanisms and Biomarkers of Exercise-Induced Bronchoconstriction. Immunol Allergy Clin North Am. (2018) 38:165-82. doi: 10.1016/j.iac.2018.01.008

27. Maher SA, Birrell MA, Adcock JJ, Wortley MA, Dubuis ED, Bonvini SJ, et al. Prostaglandin D2 and the role of the DP1, DP2 and TP receptors in the control of airway reflex events. Eur Respir J. (2015) 45:110818. doi: 10.1183/09031936.00061614

28. Hallstrand TS, Debley JS, Farin FM, Henderson WR, Jr. Role of MUC5AC in the pathogenesis of exercise-induced bronchoconstriction. J Allergy Clin Immunol. (2007) 119:1092-8. doi: 10.1016/j.jaci.2007.01.005

29. Lammers N, van Hoesel MHT, Kamphuis M, Brusse-Keizer M, van der Palen J, Visser R, et al. Assessing exercise-induced bronchoconstriction in children; the need for testing. Front Pediatr. (2019) 7:157. doi: 10.3389/fped.2019. 00157

30. Lammers N, van Hoesel MHT, Brusse-Keizer MGJ, van der Palen J, Spenkelink-Visser R, Driessen JMM, et al. Can pediatricians assess exerciseinduced bronchoconstriction from post-exercise videos? Front Pediatr. (2020) 7:561. doi: 10.3389/fped.2019.00561

31. Stevens D, Oades PJ, Williams CA. Airflow limitation following cardiopulmonary exercise testing and heavy-intensity intermittent exercise in children with cystic fibrosis. Eur J Pediatr. (2015) 174:251-7. doi: 10.1007/s00431-014-2387-2

32. Dryden DM, Spooner CH, Stickland MK, Vandermeer B, Tjosvold L, Bialy L, et al. Exercise-induced bronchoconstriction and asthma. Evid Rep Technol Assess (Full Rep). (2010) 189:1-154, v-vi.

33. Dalabih $M$, Olin JT. Exercise challenge to test for exerciseinduced bronchoconstriction. Am J Respir Crit Care Med. (2020) 202:P1-2. doi: 10.1164/rccm.2021P1

34. Keijzer PB, van der Kamp MR, Thio BJ, de Jongh FHC, Driessen JMM. Assessing paediatric exercise-induced bronchoconstriction using electromyography. ERJ Open Res. (2020) 6:002982019. doi: 10.1183/23120541.00298-2019

35. Weiler JM, Hallstrand TS, Parsons JP, Randolph C, Silvers WS, Storms WW, et al. Improving screening and diagnosis of exercise-induced bronchoconstriction: a call to action. J Allergy Clin Immunol Pract. (2014) 2:275-80.e7. doi: 10.1016/j.jaip.2013.11.001

36. Wanrooij VH, Willeboordse M, Dompeling E, van de Kant KD. Exercise training in children with asthma: a systematic review. Br J Sports Med. (2014) 48:1024-31. doi: 10.1136/bjsports-2012-091347

37. Wu X, Gao S, Lian Y. Effects of continuous aerobic exercise on lung function and quality of life with asthma: a systematic review and meta-analysis. J Thorac Dis. (2020) 12:4781-95. doi: 10.21037/jtd-19-2813

38. Kojima N, Ohya Y, Futamura M, Akashi M, Odajima H, Adachi Y, et al. Exercise-induced asthma is associated with impaired quality of life among children with asthma in Japan. Allergol Int. (2009) 58:18792. doi: 10.2332/allergolint.08-OA-0034

39. Johansson H, Norlander K, Janson C, Malinovschi A, Nordang L, Emtner M. The relationship between exercise-induced bronchial obstruction and health related quality of life in female and male adolescents from a general population. BMC Pulm Med. (2016) 16:63. doi: 10.1186/s12890-016-0226-0

Conflict of Interest: The authors declare that the research was conducted in the absence of any commercial or financial relationships that could be construed as a potential conflict of interest.

Publisher's Note: All claims expressed in this article are solely those of the authors and do not necessarily represent those of their affiliated organizations, or those of the publisher, the editors and the reviewers. Any product that may be evaluated in this article, or claim that may be made by its manufacturer, is not guaranteed or endorsed by the publisher.

Copyright (c) 2022 Klain, Indolfi, Dinardo, Contieri, Decimo and Miraglia Del Giudice. This is an open-access article distributed under the terms of the Creative Commons Attribution License (CC BY). The use, distribution or reproduction in other forums is permitted, provided the original author(s) and the copyright owner(s) are credited and that the original publication in this journal is cited, in accordance with accepted academic practice. No use, distribution or reproduction is permitted which does not comply with these terms. 